\section{Witchcraft in Swaziland}

DURING the past week the Judicial Committee of the Privy Council has had before it the appeal of a Swazi subordinate chief, Fakisandhla Nkambule, against a judgment of the Swaziland court, by which he was convicted of having through a witch-doctor procured the death of one of his wives, his brother and his brother's wife. Among the grounds of appeal, it was submitted that the plea of guilty by the witchdoctor had been allowed to prejudice his case. The statements in the case throw an interesting, if somewhat lurid, light on the strength of Swazi belief in witcheraft, which the British administration has for long made strenuous efforts to suppress. It would appear that during the ceremony of placing the ghost rope over a grave to prevent the egress of the ghost, some twenty persons who were present, seated around a cauldron over a fire, partook of 'medicine' into which it is alleged commercial arsenic had been introduced. In the result, it was claimed, three of them had died.

Some hesitation was expressed by the appellant's counsel, Mr. Horace Douglas, in accepting the statement that in Swaziland a rope was believed to be an efficient barrier to a ghost's emergence from the grave; but he was reassured on finding the Greeks and Romans had used rope to keep evil spirits from their houses. Had the learned counsel referred to the works of Sir James Frazer, he would have found ample confirmation in many varied forms. In Swaziland itself the efficacy of the grass rope as a protection against the spirit of the departed is vouched for by the fact that for a certain period the widowed man or woman always wears a grass rope, the 'grave rope', around waist or neck, and this must on no account be removed until the ceremonial period has elapsed.

\section{Austrian Academy in Great Britain}

AMONG the thousands of refugees from Central Europe who have arrived in Great Britain during the past eight years or so have been many Austrians, debarred from their own country by their political opinions or by their race. Their numbers have included many eminent scholars, who have been allowed to make their homes in Britain; they feel now that they can discharge a part of the debt of gratitude they owe by contributing to the intellectual life of the country a fuller knowledge of the cultural achievements of Austria. To this end an Austrian Academy in Great Britain has been founded, the honorary president of which is Sir George Franckenstein, formerly Austrian Minister in Great Britain. The Academy is arranging lectures, which will be delivered, as a rule, in English, and will be open to the public, on Austrian culture, and it is hoped to organize exhibitions and other activities in collaboration with the Austrian Circle for Arts and Sciences.

The inaugural meeting of the Academy will be held at the Royal Institution on May 2; among the speakers will be Prof. Gilbert Murray, Prof. E. Schrödinger (for the Austrian Academy) and Sir William Bragg. A "Society of Friends of the Austrian Academy" has been established to collaborate with the Academy and to further its scientific and cultural activities. Members of the Society will be admitted free of charge to all regular lectures, and will have special privileges for other functions arranged by the Academy. The annual contribution is one guinea. Application for membership and subscriptions should be sent to the Hon. Vice-President of the Committee of the Austrian Academy in Great Britain, Baron Guido Fuchs, 15 Portman Square, London, W.1.

\section{Industrial Health in War-time}

The Industrial Health Research Board of the Medical Research Council has published a short report on this subject (Emergency Report No. 1. H.M. Stationery Office. $6 d$. net). It is a summary of research findings, and it is claimed that by adoption of measures recommended, the efficiency, health and comfort of factory workers can be improved, production increased and discontent and fatigue avoided. Recommendations respecting work and fatigue suggest the avoidance of over-long hours and continuous work without intervals for rest, maintenance of Sunday rest and ordinary holidays, alleviation of boredom and elimination of unnecessary movements and effort. For efficient working, sufficient illumination and its proper control and distribution are necessary. Proper heating, the temperature varying with the kind of work, should be maintained, together with adequate ventilation and air movement, and a relative humidity not generally exceeding 70 per cent. A study of the causation of accidents is needed, from which may emerge means for their diminution and prevention. Lastly, recording and analysis of causes of sickness absence and accidents may contribute much information on loss of efficiency and well-being.

\section{Chemistry of Foods}

During the twelve years in which the Medical Research Council has supported Dr. McCance and his colleagues, the scope of their inquiries has been extended from determinations of the amount of carbohydrate in foods used in the treatment of diabetes to determinations of all the important organic and mineral constituents of foods, with the exception of the vitamins ("The Chemical Composition of Foods". By R. A. McCance and E. M. Widdowson. Med. Res. Council Special Report Series, No. 235. H.M. Stationery Office, 1940). Foods have been analysed, both raw and as prepared for the table, and studies have been made of the losses introduced by cooking.

The present volume includes previously published figures (Reports Nos. 135, 187 and 213), and contains all the quantitative data, in tabular form, likely to be required for work involving detailed knowledge of the chemical composition of British foods. Various facts receive comment. For example, 'Bovril' contained more potassium (3.59 per cent) than any other food examined, parmesan cheese more calcium (1.22 per cent), 'Marmite' more phosphorus (1.89 per cent), carrageen moss more magnesium $(0.63$ per cent) and sulphur (5.46 per cent), curry powder more iron $(0.075$ per cent $)$, liver more copper $(0.0058$ per cent $)$, and Gruyère cheese more nitrogen ( 5.9 per cent). 